\title{
GOVERNANÇA NO DESENVOLVIMENTO SUSTENTÁVEL NA AMAZÔNIA:ARQUITETURAS INSTITUCIONAIS E CADEIAS DE SOCIOBIODIVERSIDADE \\ GOVERNANCE FOR SUSTAINABLE DEVELOPMENT IN THE AMAZON: INSTITUTIONAL ARCHITECTURES AND SOCIO-BIODIVERSITY CHAINS
}

\author{
Fausto Makishi ${ }^{1}$ \\ João Paulo Candia Veiga ${ }^{2}$ \\ Murilo Alves Zacareli ${ }^{3}$ \\ Vivian Lara dos Santos Silva ${ }^{4}$ \\ Holmer Savastano Júnior ${ }^{5}$
}

\section{Resumo}

O trabalho, apresentado na forma de ensaio, discute a governança em políticas públicas de desenvolvimento sustentável na Amazônia com foco nas cadeias da sociobiodiversidade. O conceito de arquitetura institucional é utilizado para descrever um arcabouço de incentivos (públicos e privados) capazes de fomentar iniciativas efetivamente rentáveis, de impacto social e ambientalmente adequados no contexto rural e florestal. A teoria de custos de transação ajuda a entender como o Estado participa dessas arquiteturas diminuindo riscos e fomentando investimentos coordenados em ativos específicos, oferecendo uma visão de futuro e mediando conflitos ao longo do processo de implementação das políticas públicas. O conceito de governança é utilizado dentro de uma perspectiva ampliada, relacionada à complexidade do contexto em que acontece a cooperação entre stakeholders para a produção de incentivos locais que resultem no desenvolvimento social e ambiental. O caso da Amazônia ilustra com essas arquiteturas se desenvolvem por meio de complexo tecido de relações que potencializam ganhos econômicos privados e valorização da floresta em pé.

Palavras-chave: Amazônia. Arranjos Institucionais. Biodiversidade. Políticas Públicas. Sustentabilidade.

${ }^{1}$ Doutor em Ciências da Engenharia de Alimentos pela Universidade de São Paulo e docente no Programa de Pós-Graduação em Sociedade, Ambiente e Território da Universidade Federal de Minas Gerais, Montes Claros, Minas Gerais, Brasil. E-mail: faustomakishi@gmail.com.

2 Doutor em Ciências Políticas pela Universidade de São Paulo e docente no Departamento de Ciência Política e no Instituto de Relações Internacionais da Universidade de São Paulo, São Paulo, São Paulo, Brasil. E-mail: candia@usp.br

3 Doutor em Relações Internacionais pela Universidade de São Paulo e pesquisador no Centro de Estudos das Negociações Internacionais (CAENI) do Instituto de Relações Internacionais da Universidade de São Paulo, São Paulo, São Paulo, Brasil. E-mail: murilo.alveszacareli@gmail.com.

${ }^{4}$ Doutora em Engenharia de Produção pela Universidade Federal de São Carlos e professora associada no Departamento de Engenharia de Alimentos da Universidade de São Paulo, Pirassununga, São Paulo, Brasil. E-mail: vivianlara@gmail.com.

5 Doutor Engenharia e Construção Civil e Urbana pela Universidade de São Paulo e Professor Titular na Faculdade de Zootecnia e Engenharia de Alimentos da Universidade de São Paulo, Pirassununga, São Paulo, Brasil. E-mail: holmersj@usp.br. 


\section{Abstract}

This essay discusses governance in public policies for sustainable development in the Brazilian Amazon, with a focus on socio-biodiversity chains. The concept of institutional architecture is used to describe a framework of incentives (public and private) capable of promoting effectively profitable initiatives, with social and environmentally appropriate impact in the rural and forest context. The theory of transaction costs helps to understand how the State participates in these architectures, reducing risks and promoting coordinated investments in specific assets, offering a vision of the future, and mediating conflicts throughout the process of public policy implementation. The concept of governance is used within an expanded perspective, with complexity in the context in which cooperation between stakeholders occurs to produce local incentives that result in social and environmental development. The case of the Amazon illustrated with these architectures can be developed through a complex fabric of relationships that enhances private economic gains and values the standing forest.

Keywords: Amazon. Institutional Arrangements. Biodiversity. Public Policies. Sustainability.

\section{INTRODUÇÃO}

O Brasil é um país de dimensões continentais que concentra, em seus biomas terrestres e marinhos, mais de $20 \%$ de todas as espécies vivas conhecidas do planeta. (MAURY, 2002). Por essa razão, a biodiversidade brasileira, em especial a Amazônia, é assunto de destaque no debate travado a nível nacional e internacional sobre políticas de proteção ambiental. A este rico patrimônio genético, soma-se a diversidade de grupos sociais, étnicos e culturais que interagem com o meio ambiente, como é o caso das populações tradicionais (indígenas, ribeirinhos, camponeses, quilombolas, agricultores familiares etc.), que vivem e sobrevivem na floresta. (ALMEIDA; ALVES; PIRES, 2012).

No caso da Amazônia, destaca-se ainda o papel da floresta tropical em serviços ecossistêmicos, a exemplo da manutenção da temperatura e da umidade, bem como na absorção e armazenamento de dióxido de carbono atmosférico. (SKOLE et al, 1994; FOLEY et al., 2007; MALHI, et al, 2008).

Por sua vez, a política ambiental brasileira sofreu significativas mudanças, evoluindo ao longo nas últimas três décadas, saindo de uma lógica de instituições, majoritariamente, restritivas, voltadas a proibição de uso e 'administração' dos recursos naturais, para construção de uma agenda mais participativa, menos centralizada, mais contextualizada localmente, a favor do uso sustentável dos recursos naturais e valorização da biodiversidade.

Sobre essa perspectiva, a exploração responsável de recursos naturais não madeireiros pode servir de alternativa à geração de trabalho e renda, promovendo desenvolvimento e inclusão socioeconômica junto as comunidades locais, ao mesmo tempo em que valoriza a floresta em pé. (SACHS; WARNER, 2001; BENNETT; ROBINSON, 2000; MAKISHI et al. 2015). Essa ideia colocou a política ambiental brasileira como destaque mundial na elaboração democrática de mecanismos econômicos de proteção e exploração sustentável da floresta em pé. (ABRAMOVAY, 2019).

Essa nova forma de entender a proteção ambiental, está presente no Plano Nacional de Promoção das Cadeias de Produtos da Sociobiodiversidade (PNPSB), lançado em 2009. O referido plano congrega esforços do governo federal, representantes da sociedade civil e do setor privado em torno de uma agenda de ações voltadas à conservação e o uso sustentável da biodiversidade, bem como a garantia de alternativas de geração de renda para as comunidades rurais, por meio do acesso à crédito, à assistência técnica e extensão rural, à mercados e instrumentos de comercialização e à política de garantia de preços mínimos. (BRASIL, 2009). 
O Plano Nacional define como produtos da sociobiodiversidade:

\begin{abstract}
Bens e serviços (produtos finais, matérias primas ou benefícios) gerados a partir de recursos da biodiversidade, voltados à formação de cadeias produtivas de interesse dos povos e comunidades tradicionais e de agricultores familiares, que promovam a manutenção e valorização de suas práticas e saberes, e assegurem os direitos decorrentes, gerando renda e promovendo a melhoria de sua qualidade de vida e do ambiente em que vivem. (BRASIL, 2009, p. 9).
\end{abstract}

Chama a atenção na definição em tela o conceito de 'sociobiodiversidade', que visa incorporar à pauta ambiental aspectos sociais relacionados a questões como comportamento, tradição, cultura e conhecimento comunitário, alinhando-se à perspectiva de desenvolvimento participativo. (TOMPSON; SCOONES, 2009). Em outras palavras, o conceito de sociobiodiversidade coloca as populações tradicionais e comunidades locais no centro do processo de desenvolvimento; sustentável local, oportunizando a obtenção de riquezas econômicas e ganhos sociais, bem com a valorização da floresta em pé, evitando a destruição dos serviços ecossistêmicos. (ABRAMOVAY, 2019).

Diferentemente de outras políticas desenvolvimentistas passadas voltadas ao crescimento econômico e exploração da Amazônia, como o caso do Programa de Polos Agropecuários e Agrominerais da Amazônia - Poloamazônia, que buscou criação de enclaves industriais baseados em grades setores exportadores de commodities, a PNPSB, além de amplitude nacional, procura incorporar aspectos mais voltados a valorização ao conhecimento material e as atividades já existentes no espaço local.

Entende-se que no caso das comunidades tradicionais, a manutenção dos níveis de bemestar social está intimamente ligada ao desenvolvimento de atividades relacionadas à subsistência das famílias e indivíduos, bem como o abastecimento de mercados locais. (NAUGHTON-TREVES; HOLLAND; BRANDON, 2005; BENNETT; ROBINSON, 2000).

Conforme abordam Cazella, Bonnal \& Maluf (2009), também Renting et al. (2009), a unidade rural de base familiar - onde se incluem a maior parte das comunidades tradicionais - deve ser vista não pela lógica econômica-racional de unidade produtiva, mas como unidade multifuncional e complexa, a luz das relações sociais e afetivas, regras informais, tradições e trajetórias históricas. Isso fica bastante evidente ao observar o extrativismo e a produção de alimentos tradicionais na Amazônia, a exemplo da produção de farinha de mandioca, da pesca artesanal, da coleta de açaí e outros recursos florestais não madeireiros.

A estruturação das chamadas cadeia da sociobiodiversidade procura considerar essas necessidades e contextos locais de subsistência ao mesmo tempo em que busca a valorização de ativos latentes e estratégias de diferenciação pautadas na territorialidade, possibilitando ganhos econômicos, sociais e ambientais muito mais efetivos que nas cadeias de commodities tradicionais. (PECQUEUR, 1996; GIACOMINI; MANCINI, 2015).

Por sua vez, a viabilidade de exploração dessas potencialidades territoriais irá depender da capacidade de construir arranjos institucionais a fim de promover ações coletivas e coordenação sistêmica entre agentes locais e superar as restrições de padronização e escala impostas pelo mercado. Neste contexto, o conceito de governança ganha um sentido bastante amplo ligado à capacidade de fomentar, desenvolver e monitorar a coordenação e cooperação entre os diferentes atores de naturezas distintas que compõe o tecido social, político e econômico em que tais arranjos se desenvolvem.

No âmbito das cadeias da sociobiodiversidade da Amazônia, objeto do presente artigo, a discussão envolvendo a governança torna-se ainda mais desafiadora, dado suas particularidades 
políticas, antropológicas, culturais, sociais, biológicas e econômicas. (BENCHIMOL, 1992; ROSTONEN, 2008; ALMEIDA; ALVES; PIRES, 2012).

Nesse contexto, a questão que surge e permeia o presente trabalho é: Como construir um arcabouço de incentivos (públicos e privados) capazes de fomentar iniciativas efetivamente rentáveis, de impacto social e ambientalmente adequados no contexto rural e florestal da Amazônia?

Sendoassim, oobjetivodopresente artigoédiscutiragovernançaempolíticas de desenvolvimento sustentável na Amazônia tendo como pano de fundo as cadeias da sociobiodiversidade. Para isso, lança-se mão da abordagem de arquitetura institucional vista contribuir com uma perspectiva analítica que permita visualizar e problematizar a dinamicidade das formas de organização e de atuação do Estado em suas políticas públicas de desenvolvimento local e de proteção ambiental.

\section{GOVERNANÇA, AS 'REGRAS DO JOGO’E ARQUITETURAS INSTITUCIONAIS}

Sem que seja necessário discutir detalhadamente os diferentes significados que o termo 'governança' possa assumir, como já fez Rhodes (1996), adota-se governança como perspectiva analítica-operacional que procura incorporar contextos específicos de atuação estatal e não estatal, buscando a ampliar a capacidade de efetivação das políticas públicas por parte do governo federal. (CAVALCANTE; PIRES, 2018; MARQUES, 2015). Parar esses autores, a ideia de governança como ferramenta heurística permite incorporar sobre um mesmo recorte analítico, respeitando a características especificas de cada campo e reconhecendo suas inúmeras conexões, elementos estatais e não estatais, incluindo o próprio Estado, a sociedade, a política (politics) e as políticas (policies).

A luz de uma abordagem institucionalista, a discussão que segue assume como premissa a existência de formas alternativas de coordenação e desenvolvimento econômico para além do mercado e da centralização do Estado. Nesse sentido, a governança pode ser entendida como:

Os padrões de relação entre atores estatais e não estatais, conectados por relações formais e informais, legais e ilegais, que operam nas várias faces da produção das políticas no interior de ambientes institucionais específicos e fortemente influenciados pelos legados políticos e de políticas de cada setor da política pública. (MARQUES, 2015, p. 188).

O insight para as formas alternativas de coordenação tem origem no trabalho Karl Polanyi (1944). Crítico a abordagem econômica neoclássica, Polanyi argumenta que haveria outras formas de organização para além do laissez-faire e que, na verdade, as relações econômicas, assim como outras relações sociais, seriam condicionadas por regras formais e informais, produzidas e reproduzidas ao longo do tempo. A própria atividade econômica é, antes de tudo, moldada e restringida por um conjunto de normas, regras, convenções, hábitos e valores básicos de uma sociedade, as quais foram chamadas instituições. (HOLLINGSWORTH, 2000).

As pessoas são, naturalmente, interdependentes e o bem-estar dos indivíduos é diretamente afetado pelas ações de outros. A cooperação é necessária ao funcionamento econômico e social, mas os interesses e as experiências individuais podem ser também fontes de conflitos. As instituições formais e informais fornecem ordem e previsibilidade às transações humanas. (SCHMID, 2000).

North (1990) define instituições como as "regras do jogo", restrições e normas construídas pelos seres humanos, que condicionam a interação social, econômica e política, compostas das restrições informais (sanções, tabus, costumes, tradições e códigos de conduta) e regras formais (constituições, leis e direito de propriedade). Davis \& North (1971, p.7) introduzem a ideia de arranjo institucional, entendido como "arranjos construídos entre agentes econômicos que governam a forma pela qual esses agentes econômicos podem cooperar e/ou competir". 
Duas perspectivas analíticas emergem dessa abordagem, uma centrada no ambiente institucional e outra focada no arranjo institucional. $\mathrm{O}$ ambiente institucional diz respeito à análise em um nível macro enquanto o estudo dos arranjos institucionais volta-se ao nível do microambiente, das relações entre agentes. (FARINA et al. 1997). Dito de outra forma, o ambiente institucional é constituído por um conjunto de regras políticas, sociais e legais, básicas e gerais, que estabelecem o fundamento para o funcionamento do sistema econômico. Nesse sentido, a análise do ambiente institucional se mostra útil no campo da formulação de políticas públicas tendo em vista suprir falhas de mercado, a disponibilização de bens públicos ou coletivos, a criação de regras de funcionamento e definição do direito de propriedade, ou mesmo ao regulamentar mercados incompletos. (FARINA; AZEVEDO, 2001).

Já os arranjos institucionais compreendem as regras específicas que os agentes estabelecem para si nas suas relações econômicas, políticas e sociais. (GOMIDE; PIRES, 2014). A análise dos arranjos institucionais, por sua vez, volta-se a operacionalização das políticas stricto senso. (FIANI, 2014). Sob esse prisma, o Estado, as organizações corporativas e as redes de cooperação que representam diferentes sistemas de incentivo e direcionam as atividades dos agentes econômicos. (FARINA, 1999). O melhor entendimento desse arcabouço de incentivos, controle e participação torna-se essencial à operacionalização das políticas no espaço local. (MULS, 2008).

Dentre os autores que mais avançaram nessa discussão (arranjo institucional), destacamse Oliver Williamson $(1975 ; 1996 ; 1999)$, que relaciona três níveis de análise, a saber: ambiente institucional, arranjos institucionais e indivíduos. O argumento desenvolvido por Williamson (1996) coloca que os arranjos institucionais - os quais chamou de estrutura de governança se desenvolvem dentro de limites impostos pelo ambiente institucional e pelos pressupostos comportamentais dos indivíduos.

$\mathrm{O}$ ambiente institucional encontra-se em um nível macro analítico, regras políticas, sociais e legais básicas e gerais, como já visto. Os indivíduos, por sua vez, são dotados de comportamentos próprios, em especial a racionalidade limitada, decorrente da distribuição assimétrica de informação, e o oportunismo. Os agentes econômicos, dada sua racionalidade limitada, poderão deliberar oportunamente em benefício próprio comprometendo a cooperação e a ação coletiva necessária. (WILLIAMSON,1975; 1996). As estruturas de governança oferecem incentivos e controles para que as transações ocorram. A teoria proposta por Williamson sobre estruturas de governança será retomada na seção seguinte.

Os pressupostos comportamentais adotados por Williamson em sua construção teórica se conectam a elementos da abordagem evolucionista como observam Dos Santos et al. (2014). Mais especificamente, a racionalidade limitada pode ser associada a mecanismos de aprendizagem e path dependence, já que a tomada de decisão estaria condicionada também ao acúmulo de conhecimento cognitivo e capacidade tácita anterior à relação. (DOSI, 1991). Dessa forma, a dependência da trajetória passa a ser um elemento relevante na dinâmica institucional. (NORTH, 1990).

Page (2006) relaciona a dependência da trajetória a existências de externalidades. Ao se adotar determinada prática, automaticamente diminui-se a atratividade relativa das demais alternativas existentes. As externalidades positivas criam um viés em favor de um arranjo existente enquanto as externalidades negativas criam um viés contra novos arranjos, gerando a exclusão de outras alternativas, o que implica em lock-in, i.e., irreversibilidade, e, assim, dependência da trajetória. Os benefícios relativos da atividade atual comparados às opções anteriormente possíveis aumentam com o tempo. (PIERSON, 2004).

Pierson $(2000,2004)$ identifica o conceito de path dependence com o mecanismo de retornos crescentes e processos de auto reforço, ou feedback positivo. Esses elementos explicariam a 
tendência inercial de reprodução de arranjos institucionais, gerando problemas de lock-in também na operacionalização de políticas públicas. Os resultados de um arranjo institucional tendem a retroalimentar e reforçar os laços criados, tornando os resultados alternativos menos interessantes.

De certa forma, Williamson (1975) também reconhece a existência de path dependence na medida em que descreve a frequência como dimensão da transação econômica. Para Williamson a recorrência em uma dada transação, o que é algo bastante comum na economia capitalista, estaria relacionado a aspectos de reputação e confiança, construídos ao longo do tempo.

Oreconhecimento de que a trajetória histórica e contextual interfere na forma em que os indivíduos se organizam, sugere que nenhuma ação tomada em um nível macro poderá trazer resultados idênticos ao nível micro, uma vez que as realidades são heterogêneas. A efetividade das políticas públicas está, dessa forma, intimamente ligada as relações produzidas e reproduzidas em no nível local.

Com base nisso, Gertler (2010) propõe o conceito de arquitetura institucional como forma de diferenciar esses arranjos, construídos ao longo do tempo.

As economias que são reconhecidamente capitalistas na orientação, no entanto, evoluem por caminhos distintos que são moldados por suas constelações particulares de estruturas institucionais - suas próprias arquiteturas institucionais distintas. (GERTLER, 2010, p.3).

Implícita a proposição de Gertler, a ideia de que os arranjos não estão isolados, mas sobrepostos em escalas e formas diferentes que se relacionam no espaço geográfico. A arquitetura institucional compreende também as diferentes camadas que relacionam as instituições do nível macro ao micro. Ela permite entender melhor as interações entre instituições de diferentes tipos e escalas. (VAN DEN BROEK; SMULDERS, 2013). A ideia é de arenas sobrepostas, uma estrutura multinível ou multicamada.

A perspectiva de instituições, mais especificamente o referencial de arquitetura institucional, ajuda a entender a organização como um nexo de incentivos e controles decorrentes de um arcabouço institucional que se sobrepõe e circunscreve as relações econômicas, sociais e políticas no espaço local. Desse puzzle de incentivos, permeado por relações de cooperação e conflito, emergem algumas implicações ao Estado e sua capacidade de executar suas políticas, no caso específico do presente trabalho, as políticas de proteção ambiental e desenvolvimento regional na Amazônia.

\section{MECANISMOS DE INCENTIVO E CONTROLE E ATUAÇÃO DO ESTADO NAS POLÍTI- CAS DE DESENVOLVIMENTO}

"As instituições fornecem a estrutura de incentivos em uma economia; à medida que essa estrutura evolui, ela determina a direção da mudança econômica rumo ao crescimento, ou à estagnação, ou ao declínio." (NORTH, 1991, p.97). A relação entre arranjo institucional e os mecanismos de incentivo e de controle é melhor compreendida a partir da teoria de custos de transação.

O conceito de custos de transação foi introduzido inicialmente por Ronald Coase (1937) e refere-se a custos de natureza distinta aos custos de produção, decorrentes das relações econômicas que determinam as atividades de prospecção de preços, negociação, troca, captura, coordenação, monitoramento, mensuração e proteção dos direitos de propriedade. (MILGROM; ROBERTS, 1992; FARINA et al. 1997). Em outras palavras, os custos de transação são os custos derivados da utilização de um determinado arranjo institucional com vista a coordenação entre agentes.

Dentre os autores que mais avançaram nesse assunto, destaca-se o prêmio Nobel Oliver Williamson e seus trabalhos sobre estruturas de governança. Williamson (1975) argumenta que os custos de transação derivam de três dimensões, a saber: frequência, incerteza e especificidade dos ativos. 
A frequência da transação permite a diminuição de custos decorrentes da coleta de informação e elaboração de contratos, além de possibilitar a construção de reputação entre as partes envolvidas na negociação. (FARINA et al.,1997). A recorrência da transação faz com que a confiança na ralação entre as partes aumente, diminuindo a necessidade da imposição de mecanismos de salvaguarda a medida em que uma atitude oportunista compromete as transações futuras. Tal constatação vai ao encontro da afirmação de que mecanismos de feedback contribuem para consolidação das relações no tempo, conforme discutido anteriormente.

A incerteza tem o papel de ampliar as lacunas que um contrato pode cobrir, ou seja, ela torna evidente a assimetria de informação e incapacidade de elaborar de contratos completos. (FARINA, 1999). A incapacidade de prever acontecimentos futuros tende a tornar as transações mais 'difíceis' de serem realizadas. O processo de desenvolvimento econômico por si só é repleto de incertezas, conforme observa Chang (1996), o que pode resultar em problemas do tipo lock-in.

Especificidade dos ativos, ponto central na teoria de Williamson, representa a dificuldade de reempregar determinado ativo em uma outra atividade, sem perda de valor. (FARINA et al.,1997). Os investimentos na transação realizados por uma das partes tendem a dificultar a mobilidade dessa em relação a transação. Quanto maior a especificidade dos ativos, maior a perda associada a uma ação oportunista por parte de outro agente, ou seja, há considerável diminuição de autonomia.

Ao avançar na discussão sobre arranjos institucionais, Williamson $(1985 ; 1991)$ descreve três formas discretas, o que chamou de estruturas de governança: mercado, hierarquia e híbrido. A escolha da estrutura mais eficiente em termos de custo de transação irá depender das dimensões das transações: incerteza, frequência e especificidade dos ativos. Por exemplo, se a especificidade dos ativos é baixa, a transação pode ocorrer via mercado. Já quando a especificidade dos ativos é elevada, faz-se necessária a criação de restrições formais ou mecanismos de salvaguarda que garantam a transação. Neste caso, o mercado não representa o arranjo mais eficiente à organização.

$\mathrm{Na}$ estrutura de mercado, centro da abordagem econômica neoclássica, os incentivos são dados exclusivamente por ganhos e perdas monetárias dos agentes envolvidos, o conhecido sistema de preços. Nesse caso, não há vínculo entre as partes, sendo qualquer uma delas substituíveis em qualquer momento e sem grandes esforços a contraparte na transação. A estrutura de mercado cria incentivos para a adaptação autônoma, ou seja, compradores e vendedores responderão a mudanças de preço de forma independente e espontânea. (FIANI, 2014). Exemplo desse tipo de estrutura pode ser encontrado nas bolsas de valores e na comercialização de commodities.

Por seu turno, a hierarquia corresponde à estrutura discreta cuja decisão se dá pela autoridade, pelo controle administrativo. A coordenação ocorre sob ação da burocracia ao invés de um sistema de preços. Ao contrário da situação anterior (mercado), numa hierarquia, os agentes não possuem autonomia, estando sujeitos a um controle centralizado. Não há incentivos e sim controle, trata-se de uma relação de poder e de mando. A adaptação ocorre de forma coordenada, ou seja, há esforço, consciente e deliberado, em elaborar mecanismos de coordenação interna para favorecer a adequação da transação frente as mudanças no ambiente externo. (WILLIAMSON, 1996). Exemplos clássicos dessa estrutura são as empresas privadas e estatais. A hierarquia mostra-se particularmente mais eficiente quando a transação envolve investimentos específicos, cujo valor é maior quando empregado em uma dada transação que nas alternativas.

A terceira estrutura identificada por Williamson (1996) foi chamada de arranjo híbrido e combina incentivos de mercado e controles administrativos, podendo ser reconhecidos elementos das duas outras estruturas de governança descritos anteriormente. Neste caso, ocorre um misto de adaptação coordenada e autônoma. 
O conceito de estrutura de governança ajuda a compreender o papel das instituições no processo de desenvolvimento, em especial as diferentes formas de incentivo e controle que implicam na forma de adaptação envolvida. No caso do desenvolvimento econômico, conforme observa Fiani (2011), o processo pode envolver elevados investimentos em ativos específicos. Como visto, a estrutura de mercado pode não oferecer incentivos suficientes para que tais investimentos sejam realizados, sendo necessária, em algum momento, a ação do Estado.

Nesse sentido, uma vez que o mercado não representa o arranjo mais eficiente em termos de coordenação, o Estado poderá atuar de duas outras formas: por meio da hierarquia, como ocorre tradicionalmente nos órgãos da administração direta como ministérios ou empresas estatais controladas politicamente, ou em arranjos híbridos, reunindo esforços de organizações públicas e privadas em um mesmo arranjo institucional. (FIANI, 2011).

Nos últimos anos, a discussão envolvendo estruturas de governança tem se concentrado nas relações entre atores privados, a exemplo das redes de empresas, joint ventures, franquias, cadeias de fornecedores e arranjos produtivos locais. (MÉNARD, 2010). Na maior parte das vezes os estudos envolvendo a participação do Estado tendem a ficar restritos à política industrial, à regulação macro e ao provimento de bens públicos. (FARINA et al. 1997; FIANI, 2011; CHANG, 1996). Diversos autores, entre os quais, Borys \& Jemison (1989), Vilpoux (2011) \& Fiani (2014) têm destacado a importância de um olhar mais atento a participação do Estado em arranjos institucionais, com destaque para as estruturas híbridas, como forma de implementar políticas públicas mais robustas no espaço local, a exemplo das parcerias público-privadas.

Para Fiani (2014), o fato de o arranjo híbrido poder envolver agentes públicos e privados independentes na consecução de objetivos comuns impõe problemas de cooperação e adaptação entre os agentes que são, por sua própria natureza, distintos daqueles enfrentados por uma hierarquia ou um mercado. Entretanto, conforme o mesmo autor observa: "esse tipo de abordagem do problema dos híbridos, enfatizando o papel dos atributos identificados por Williamson, não tem sido desenvolvido até o momento [na literatura]." (FIANI, 2014, p.67).

Gomide \& Pires (2014) sugerem que a atuação do Estado dentro dos chamados arranjos híbridos se dê por duas capacidades complementares: Capacidade técnico-administrativo, que deriva do conceito de burocracia e contempla as competências dos agentes do Estado para levas a feito suas políticas; e Capacidade Política, que compreende habilidades em expandir os canais de interlocução e negociação com outros atores, processando conflitos e prevenindo a captura por interesse específico. A capacidade política pode ser vista como tradução dos anseios democráticos de participação e inclusão de temas sociais na agenda pública, bem como a representação das múltiplas formas de participação dos atores sociais e políticos no processo de decisão e implementação de uma política pública.

Com base nesse argumento, Fiani (2014) descreve três formas de atuação do Estado dentro dos arranjos híbridos: (a) coordenar investimentos privados em ativos específicos, corrigindo falhas de coordenação; (b) atuar de forma empreendedora, oferecendo uma visão de futuro sobre novas possibilidades de transformação do sistema econômico; (c) administrar conflitos.

As falhas de coordenação ocorrem quando há necessidade de investimento em ativos específicos de forma coordenada vista alcançar ganhos mais elevados, porém o comportamento individual dos agentes dificulta sua realização. Nesse caso, o mercado não oferece incentivos suficientes para que um agente encete uma nova iniciativa. Isso porque o mercado cria incentivos ex post, conforme observa Chang (1996). O dilema enfrentado é que se não houver investimento, não há ganho, mas se não há ganho, não existe investimento. Desse modo, faz-se necessário um agente que garanta um movimento coordenado de todos os agentes, oferecendo um "big push" para que investimentos em ativos específicos sejam realizados. (ROSENSTEIN-RODAN, 1943; FIANI, 2014). No caso 
das cadeias produtivas, é necessário que os investimentos em ativos específicos ocorram de forma coordenada ao longo de toda cadeia, vista a criação de rendas extraordinárias.

Adicionalmente, cabe ao Estado, segundo a lógica de incerteza e complexidade das atividades produtivas, capitanear novas possibilidades de transformação do sistema econômico, em especial aquelas que fogem ao horizonte temporal do mercado corrente. Em sua função empreendedora, o Estado deve oferecer uma "visão de futuro", tendo como objetivo superar aquilo que vá além dos equilíbrios superiores atuais. (FIANI, 2014). Em outras palavras, a participação do Estado nos arranjos institucionais híbridos sugere a utilização de ferramentas e mecanismos econômicos de indução por parte deste, no lugar de comandos diretivos e autoritários.

Uma vez que a coordenação se torna indispensável ao desenvolvimento. (FARINA, 1999), a necessidade pode levar o Estado a assumir algumas funções de agentes privados, para garantir que os investimentos específicos sejam realizados nas atividades excessivamente arriscadas nas sociedades em questão, pelo elevado grau de complexidade e incerteza dessas atividades (FIANI, 2014). As compras públicas, mais especificamente os programas de Aquisição de Alimentos (PAA) e Alimentação Escolar (PNAE), podem ser dados como exemplos dessa função do Estado.

O processo de desenvolvimento é, por si só, gerador de conflitos. (FIANI, 2014). Isso porque os investimentos realizados no passado por alguns tende a provocar reações de resistência as mudanças, caso essas impliquem em diminuição do valor ou benefício provenientes da alternativa original. Petições, greves, suborno e negociatas são exemplos de ações políticas provocadas por esses agentes feridos no processo de mudança. O Estado deverá exercitar sua capacidade política para administrar conflitos, o que pode ser diminuído com a participação democrática no processo de decisão.

Em resumo, promover a coordenação e buscar novas oportunidades, estão diretamente ligadas à capacidade técnico-administrativa do Estado, enquanto a solução de conflitos remete ao exercício da capacidade política de mediação, conforme descrito por Gomide \& Pires (2014). Na prática, o que se observa não é a predominância de uma forma de atuação, mas sim a combinação de mecanismos. Uma política pública, a fim de obter resultados efetivos, deverá ajustar mecanismos de incentivo e controle de forma a diminuir riscos e fomentar investimentos coordenados em ativos específicos, oferecer uma visão de futuro e mediar conflitos ao longo do processo de implementação. Sem a pretensão de oferecer um modelo a ser seguido ou replicado, o caso das cadeias da sociobiodiversidade é utilizado como ilustração empírica para essa discussão.

\section{CADEIAS DA SOCIOBIODIVERSIDADE E OS DESAFIOS PARA O DESENVOLVIMEN- TO SUSTENTÁVEL NA AMAZÔNIA}

A retomada do discurso sobre soberania territorial da Amazônia por parte do governo brasileiro, manifestada após a ampla veiculação dos casos de incêndios florestais ocorridos em 2019, servem para reavivar um antigo - e aparentemente transposto - debate sobre os conflitos relacionados as políticas de proteção ambiental e crescimento econômico na região da Amazônia. Seguem adjacentes a essa guinada na narrativa governamental, ações promovidas em grande parte pelo próprio poder público que alimentam o descrédito a grupos de pesquisa e do terceiro setor, negação de dados e evidências científicas, bem como o processo de desmonte de órgãos ambientais de reconhecida importância no combate e monitoramento ás queimadas e derrubadas florestais.

Cabe registrar que a ideia de soberania territorial amazônica não é nova. O discurso data da instalação do Estado Novo e foi reafirmado no regime militar durante a Conferência de Estocolmo (Conferência das Nações Unidas para o Meio Ambiente Humano) em 1972, ocasião em que o governo brasileiro defendeu, contrariando o que parecia um consenso entre os participantes, o argumento de 
que o crescimento econômico dos países em desenvolvimento não poderia ser sacrificado em função da proteção ambiental. A questão ambiental só ocuparia uma posição de destaque na pauta política governamental brasileira posteriormente, a partir da Constituição de 1988. Com o passar do tempo, a ideia de desenvolvimento sustentável se consolidou nos mais diferentes meios e a narrativa de proteção ambiental como entrave ao crescimento econômico foi abandonada. (MOURA, 2016).

Aconcepção desenvolvimentista assinalada recentemente pelo governo brasileiro representa mais um capítulo de um conturbado histórico nas políticas de crescimento econômico e proteção ambiental na Amazônia, que, de certa forma, explicam, a configuração de acentuadas desigualdades socioeconômicas encontrada hoje na região. Para se ter uma ideia, o Índice de Desenvolvimento Humano Municipal, um indicador de desenvolvimento proposto pelo PNUD Brasil, o IPEA e a Fundação João Pinheiro, registram para os municípios da região denominada Amazônia Legal um IDHM de 0,683 contra 0,727 da média nacional calculada em 2010. (ATLAS BRASIL, 2014). Outro indicador, o Índice de Progresso Social (IPS), desenvolvido pela Rede Progresso Social Brasil aponta para um IPS médio da Amazônia de 56,52, também inferior à média nacional de 67,73. (SANTOS et al. 2018).

A experiência tem demonstrado que a efetividade das políticas de desenvolvimento depende, dentre outras coisas, do entendimento de como se dá as relações entre atores estatais e não-estatais nos mais diferentes níveis de análise a fim de lidar com a dinamicidade e complexidade das instituições formais e informais que circunscrevem essas relações. (GOMIDE; PIRES, 2014; CAVALCANTE; PIRES, 2018). Em outras palavras, ao analisar o histórico político desenvolvimentista da Amazônia, verifica-se que nem a centralização autoritária do Estado, nem o liberalismo econômico do mercado, presentes nas políticas de 1950 a 1990, foram capazes de oferecer uma solução eficiente em termos econômicos, sociais ou ambientais para a Amazônia.

Uma nova forma de pensar o desenvolvimento, começa a ser percebida nas políticas desenvolvidas somente a partir dos anos 2000.

Uma estratégia de desenvolvimento consistente para a Amazônia precisa apropriar essa diversidade ambiental, econômica, social, cultural e política, refletida nas unidades territoriais como elemento central de organização das ações, sob pena de não dialogar concretamente com a forças sociais atuantes em cada contexto do vasto território. (BRASIL, 2008, p.80).

Nesse sentido, resgatando a discussão que precede essa seção, o arranjo institucional deverá tornar-se objeto de análise a fim de subsidiar as estratégias governamentais vista ampliar suas capacidades da ação e alcance dos objetivos pretendidos, quaisquer que sejam. A questão é como construir um arcabouço de incentivos (públicos e privados) capaz de fomentar projetos e ações rentáveis economicamente, de impacto social e ambientalmente adequados no contexto florestal da Amazônia?

Criado em 2009, o Plano Nacional de Promoção das Cadeias de Produtos da Sociobiodiversidade (PNPSB) segue uma tendência recente de políticas públicas interministeriais e congrega esforços do Governo Federal, representado pelos ministérios do Meio Ambiente (MMA), Desenvolvimento Agrário (MDA), Desenvolvimento Social e Combate à Fome (MDS) e pela Companhia Nacional de Abastecimento (Conab), e participação direta de outros atores como Casa Civil, Agência Nacional de Vigilância e Inspeção Sanitária (ANVISA), Serviço Florestal Brasileiro (SBF), Instituto Chico Mendes de Conservação da Biodiversidade (ICMBio), Instituto Nacional de Regularização e Reforma Agrária (INCRA), Agência de Cooperação Técnica Alemã (GIZ), Empresa Brasileira de Pesquisa Agropecuária (EMBRAPA), além do setor empresarial, as agências de fomento e a sociedade civil organizada. 
Ao nível do ambiente institucional, o PNPSB se conecta a outras políticas nacionais, a exemplo da Política Nacional de Biodiversidade - PNB, implementada por meio do Decreto $\mathrm{N}^{\circ} 4.339$ em 2002 e alinhada a Convenção de Diversidade Biológica das Nações Unidas; da Política Nacional de Desenvolvimento Sustentável dos Povos e Comunidades Tradicionais (PNPCT), instituída em 2007 por meio do Decreto $n^{\circ}$ 6.040; e da Política Nacional de Desenvolvimento Regional (PNDR), estabelecida pelo Decreto $n^{\circ}$ 6.047/ 2007. Essas e outras ações compõem uma agenda maior voltada a articulação política e social que assinala a construção de um arcabouço institucional intersetorial e democrático que fizeram do Brasil referência mundial na elaboração de mecanismos econômicos voltados à proteção e à exploração sustentável da floresta em pé. (ABRAMOVAY, 2019).

Adicionalmente, o PNPSB parece ter encontrado na maior floresta tropical do mundo um contexto institucional favorável para desenvolver estratégias de desenvolvimento baseadas na exploração responsável de recursos não madeireiros. Ainda que as ações do referido plano se estendam por todos os biomas do território nacional, há sob a Amazônia, como será visto, uma forte arquitetura institucional construída ao longo dos anos.

A relação das comunidades tradicionais com a floresta é um fato histórico e representa um aspecto fundamental para a compatibilização da sua exploração sustentável. As drogas do sertão existem desde muito antes de se pensar em 'ocupar' a Amazônia. A floresta constitui um potencial de extrema relevância para ganhos econômicos, tanto para as comunidades locais quanto para o setor privado. São mais de 33 mil espécies de plantas superiores, pelo menos 10 mil delas portadoras de princípios ativos para uso medicinal, cosmético e controle biológico de pragas, além de 300 espécies de frutas comestíveis e uma rica fauna silvestre. (BRASIL, 2008).

Há de se reconhecer que a exploração sustentável de recursos florestais não madeireiros é ainda pouco significativa em termos macroeconômicos, mas representam uma atividade tradicional importante para sobrevivência das populações tradicionais e agroextrativista, em vista sua subsistência e manutenção econômica. Outras cadeias começam a romper essa ideia e vêm se destacando no mercado nacional e internacional, a exemplo do açaí, da borracha, da copaíba e da castanha do Brasil. Nesse sentido, o PNPSB reforça a função do Estado em oferecer uma visão de futuro sobre o potencial econômico dos biomas brasileiros.

Nota-se que a ideia de crescimento econômico alinhado à proteção ambiental, bem como à exploração sustentável de recursos florestais não madeireiros, já se fazia presente no Plano Amazônia Sustentável - PAS, lançado pelo Governo Federal em 2008. Dentre os compromissos apresentados no referido plano com foco regional, destaca-se o primeiro ponto listado como: "Promover o desenvolvimento sustentável com valorização da diversidade sociocultural e ecológica e redução das desigualdades regionais. (BRASIL, 2008). Presente tanto no PAS quanto na PNPSB a ideia de que crescimento econômico da Amazônia independe da substituição da floresta por áreas dedicadas a atividades agropecuárias tradicionais como o cultivo de soja e criação de gado. (ABRAMOVAY, 2019).

A construção democrática e participativa dessas agendas políticas, com forte envolvimento de representações da sociedade civil e setores empresariais, é um ponto que também merece destaque e favorece a construção de arranjos institucionais híbridos.

Junto ao setor privado, as cadeias da sociobiodiversidade têm atraído a atenção da indústria processadora, interessada em explorar insumos da biodiversidade e atender à crescente demanda, sobretudo em países desenvolvidos, por produtos funcionais e exóticos, valorizados por princípios da preservação ambiental e relações comerciais mais justas.

Para Ferro et al., (2006), avanços tecnológicos ocorridos nos últimos anos junto à indústria processadora, como a identificação de compostos ativos e melhorias na capacidade de processamento, corroboram para a valorização da biodiversidade. Vide exemplo da indústria de beleza e cuidados 
pessoais (beauty and personal care) que, apesar da recente crise econômica mundial, apresenta taxas relativamente elevadas de crescimento, movimentando em 2018 cerca de U\$ 480 bilhões. (EUROMONITOR, 2019). Não por acaso, a Pesquisa \& Desenvolvimento está presente em todos os seis eixos de ação do PNPSB.

A participação do setor privado em ações, programas e políticas de redução da pobreza e da desigualdade social, bem como o alívio no uso de recursos naturais é um fenômeno relativamente recente. As empresas, ONGs, as comunidades locais e o poder público (local e regional) articulamse para a provisão de instrumentos de gestão mais eficientes com a legitimidade conquistada pelos resultados alcançados (impacto social e ambiental). Da mesma forma, essa arquitetura institucional ganha relevância ao articular ONGs, organizações internacionais e governos nacionais com a regulação internacional para a biodiversidade, em negociação no âmbito da Convenção da Biodiversidade das Nações Unidas, e com o Protocolo de Nagoya. (MAKISHI et al. 2016).

O papel do setor privado é impulsionado pelo processo de integração global em curso e os temas ambientais e sociais estão cada vez mais interconectados e as fronteiras formais dos Estados se abrem aos incentivos da cooperação entre empresas e ONGs, através de instrumentos de governança mais eficientes que assumem funções regulatórias. (MATHEWS, 1997; RISSE-KAPEN, 1995; LACHER, 2003; JOSSELIN; WALLACE, 2001).

$\mathrm{O}$ conceito de governança ganhou ampla abrangência e a sua definição está relacionada à complexidade do contex to em que acontece a cooperação entre stakeholders para a produção de incentivos locais que resultem no desenvolvimento social e ambiental. (ROSENAU, 2000; NAYYAR, 2002; DINGWERTH \& PATTBERG, 2006). Muls (2008), destaca que a formação dessas redes de relações sociais, econômicas e políticas no espaço local, emerge de modelos de governança “intermediários" entre a intervenção centralizadora do Estado e o carácter auto regulador do mercado. Nestas novas formas de coordenação, comandos diretivos e autoritários antes utilizados pelo poder público vão dando lugar a novas ferramentas e mecanismos econômicos indutores do mercado, onde a busca por cooperação e solução de conflitos tornam-se objetos de planejamento e operacionalização. (GOMIDE; PIRES, 2014). Em outras palavras, cabe ao poder público, não só a regulação e monitoramento, mas também a provisão de informações e mediação entre os interesses sociais e diferentes agendas privadas.

Ros-Tonen et al. (2008), observam que a ideia de governança assume, no âmbito das atividades rurais e florestais, duas dimensões que são complementares. A primeira, de natureza política, tem como objetivo a geração de mudanças orientadas através de um arcabouço institucional, compostos de regras e mecanismos de fiscalização favoráveis ao uso sustentável da biodiversidade e a segunda dimensão tem como foco as relações produtivas, de divisão do trabalho ao longo da cadeia e com o objetivo de viabilizar economicamente e logisticamente o uso sustentável de recursos florestais.

Essas duas dimensões de governança (política e corporativa), vertem sobre a necessidade de diálogo intersetorial, envolvendo diferentes atores estatais e não-estatais e na busca de sinergia entre perspectivas e interesses distintos. Contudo, conforme observa Fiani (2014), a operacionalização destes arranjos institucionais híbridos tem-se mostrado bastante difíceis e pouco comuns em meio às políticas públicas nacionais e territoriais.

Evidentemente, nem toda atividade econômica desenvolvida na região tem contribuído para o desenvolvimento sustentável da Amazônia; a extração de madeira, a pesca industrial, a pecuária e agricultura extensiva, a mineração e, recentemente, a geração de energia, têm dividido opiniões sobre o rumo do desenvolvimento levado para esta região. Embora esses empreendimentos transfiram uma quantidade significativa de recursos financeiros para região, acredita-se que a dependência dessas fontes de riqueza, além dos impactos ambientais conhecidos, levaria a uma especialização não sustentável da economia local. Essa é a ideia que vem sendo chamada de nova "doença holandesa" 
ou "maldição dos recursos naturais". (SACHS; WARNER, 2001; STIGLITZ, 2004; BRESSERPEREIRA; GALA, 2010; FRANKEL, 2010), quando a exploração econômica de um determinado recurso abundante tende a minar a exploração de outras fontes econômicas, muitas vezes essenciais à manutenção e resiliência das populações locais. Isso reforça a necessidade de o Estado exercer sua capacidade política, administrando conflitos e interesses parciais e imediatistas, por meio da construção democrática e participativa.

Neste contexto, a centralidade na agricultura familiar e nas comunidades tradicionais representa outro ponto de destaque nas políticas em tela e estabelece outras conexões com a agenda política nacional que começa a se consolidar em 2003 com o lançamento do Fome Zero, oferecendo também uma resposta a alguns anseios de organismos internacionais como as Nações Unidas, a FAO, o PNUD e o Banco Mundial.

A esse respeito, observa-se que a inserção sustentável da agricultura familiar e das comunidades tradicionais em cadeias de valor, é um tema bastante debatido na literatura mundial e se insere em uma agenda maior de preocupações, que desafia o poder público e privado em diferentes aspectos. $\mathrm{O}$ assunto vai ao encontro de tópicos de grande repercussão, como segurança alimentar e nutricional, alterações ambientais provocadas pelo homem, fixação do homem no campo, melhoria nas condições de saneamento e de higiene, diminuição da pobreza, sobrecarga dos gastos públicos - decorrentes de políticas de subsídios, busca pelo desenvolvimento de relações econômicas mais justas e a preservação da biodiversidade e da cultura tradicional. (ABRAMOVAY, 1998; SACHS; WARNER, 2001; SCHNEIDER, 2003; CAZELLA, BONNAL, MALUF, 2009).

A discussão parece relevante no caso específico da Amazônia, onde acredita-se que a proteção da biodiversidade está fortemente atrelada à manutenção de renda e subsistência em comunidades agroextrativistas; as quais são desenvolvedoras de atividades econômicas ambientalmente responsáveis. (SANTOS et al. 2018; BENCHIMOL, 1992; NAUGHTON-TREVES; HOLLAND; BRANDON, 2005). Conforme argumenta Abramovay (2019), as comunidades tradicionais possuem singular vocação para desempenhar papel de prestadoras de serviços ecossistêmicos.

Em grande medida, essa forma de entender a multifuncionalidade da agricultura familiar (CAZELLA, BONNAL, MALUF, 2009) está presente no Plano Amazônia Sustentável, "na ordem de importância, os produtos naturais existentes atendem ao próprio consumo, ao mercado interno e ao externo, com tendência crescente a mercantilizar e aumentar o seu âmbito geográfico de comércio. (BRASIL, 2008, p. 41)".

No PNPSB, embora não se identifique uma ação concreta voltada para subsistência, as atividades de produção e extrativismo para o auto abastecimento são reconhecidas, sendo a segurança alimentar e nutricional uma das diretrizes do Plano Nacional. Em complemento, nota-se no referido plano a preocupação em fomentar circuitos de abastecimento local, ampliando o acesso a esses mercados, incentivando a criação de feiras, centrais de comercialização, polos de recepção de produtos do extrativismo e redes de comercialização de produtos da sociobiodiversidade. (BRASIL, 2009).

Destaca-se nessa articulação mais ampla que circunscreve as políticas de desenvolvimento econômico e proteção ambiental na Amazônia três ações do governo federal, a saber: O Programa de Fortalecimento da Agricultura Familiar (Pronaf), em suas linhas de crédito específicas Pronaf-Floresta e Pronaf-Agroecologia, o Programa de Aquisição de Alimentos (PAA) e Política de Garantia de Preços Mínimos para os Produtos da Sociobiodiversidade (PGPM-Bio). Estas ações, mas especificamente o crédito, a construção de mercados e a diminuição dos efeitos de oscilação de preço, reforçam a necessidade de buscar complementariedade nas políticas públicas, ao institucionalizar mecanismos incentivo à investimentos coordenados em ativos específicos ao longo da cadeia produtiva, corrigindo algumas falhas de mercado. 
No âmbito da Amazônia, o que ocorre na prática, não é exatamente a ausência do Estado e sim uma certa "avalanche" de incentivos nem sempre convergentes; participando deste puzzle de incentivos, o setor privado (indústria processadora e mercados locais) e a ação de organizações nãogovernamentais. O grande desafio é encontrar sinergias entres essas inúmeras ações.

Parte desse quebra-cabeças institucional, pode ser compreendido através da adaptação do conceito de arquiteturas institucionais; neste caso, o que define essas arquiteturas está diretamente ligado ao ambiente institucional que caracteriza o macro universo (leis, políticas e normas nacionais e internacionais), mas, principalmente as relações entre agentes estabelecidos no nível regional e local. Incluem-se nestes os laços horizontais da comunidade, associações e cooperativas e relações verticais, estabelecidas entre segmentos ao longo das cadeias de valor. Ou seja, a divisão de trabalho local, baseado em uma especialização de atividades desenvolvidas, resulta de uma combinação de incentivos provenientes das políticas públicas, ações não governamentais, relações sociais e o mercado. Assim, a eficiência aqui não está ligada à competição de mercado, mas a sobrevivência das famílias e aos ganhos de bem-estar trazidos pela combinação entre diferentes atividades e incentivos.

\section{CONCLUSÕES}

O presente ensaio procurou fomentar a discussão envolvendo a governança em políticas de desenvolvimento sustentável na Amazônia utilizando como o objeto de estudo as cadeias da sociobiodiversidade.

O conceito de arquitetura institucional, ajuda a entender a efetividade das políticas de desenvolvimento como dependente das relações entre atores estatais e não-estatais nas diferentes camadas de governo dispostas em arenas sobrepostas. Trata-se de uma construção de governança multinível, cuja atuação do Estado se dá por meio da combinação de mecanismos de incentivos e controle, chancelados pelas relações locais envolvendo setor empresarial e sociedade civil. Em outras palavras, a promoção de crescimento econômico, bem-estar social e preservação ambiental, dependem do delineamento de uma estrutura complexa e dinâmica de mecanismos de incentivo e controle, envolvendo vários agentes em diferentes níveis adequados à exploração das potencialidades específicas de cada local e região; favorecendo o desenho de estratégias verdadeiramente sustentáveis de coordenação e cooperação interorganizacionais, criadoras de impacto econômico, social e ambiental.

O conjunto de ações nacionais e supranacionais de desenvolvimento sustentável e proteção do meio ambiente capitaneados pelo governo brasileiro nas últimas três décadas, com participação ativa da sociedade e dos setores empresariais, contribuem com um ambiente institucional favorável para o fortalecimento das cadeias da sociobiodiversidade na Amazônia, considerando o potencial biológico já existente e o conhecimento material das comunidades tradicionais que ali estão. Ao fomentar o uso sustentável de recursos florestais não madeireiros como fonte de crescimento econômico e valorização da floresta em pé, o Estado oferece novas possibilidades de transformação do sistema econômico regional, rumo à sustentabilidade.

Da formação dessas arquiteturas institucionais compostas por relações sociais, econômicas e políticas no espaço local, emergem modelos de governança “intermediários" entre a intervenção centralizadora do Estado e o carácter auto regulador do mercado. Nestas estruturas híbridas, comandos diretivos e autoritários antes utilizados pelo poder público vão dando lugar a novas ferramentas e mecanismos econômicos indutores do mercado, onde a busca por cooperação e solução de conflitos tornam-se objetos de planejamento e operacionalização governamental. Ou seja, afetividade das políticas de desenvolvimento sustentável dependem das capacidades técnico-administrativo e 
política do Estado, respectivamente, sua competência de formular e levar a feito suas políticas e suas habilidades em expandir os canais de interlocução e negociação com outros atores, processando conflitos e prevenindo a captura por interesses específicos.

Na contramão dessa perspectiva, a política desenvolvimentista assinalada recentemente pelo governo brasileiro, sob os argumentos de defender a Amazônia e de expandir para alimentar o mundo, rompe com a lógica por trás do arcabouço institucional criado ao longo das últimas três décadas para valorização e preservação da principal floresta tropical do mundo. Os resultados dessas políticas são bem conhecidas e refletem no desmatamento, nos índices de miséria e violência encontrados hoje na região.

No que segue, o debate contemporâneo envolvendo a governança das políticas de desenvolvimento supera a ideia irrealista e, até certo ponto, é ingênua de planos, reformas e propostas do tipo one-size fits all model, passando a valorizar a combinação de tendências que possibilitam implementar soluções inovadoras e efetivas para os problemas públicos, cada vez mais complexos, transversais e incertos. Na Amazônia, esses problemas mostram-se ainda mais complexos e incertos.

Conforme descreve Fiani (2014), dentre outros, a discussão do papel do Estado em arranjos institucionais híbridos ainda é pouco explorada na literatura. Outros estudos, incluindo análises de natureza empírica, devem ser desenvolvidos a fim de iluminar melhor estas questões e contribuir para formulação e operacionalização de políticas públicas mais efetivas em seus impactos junto à sociedade, ao meio ambiente e à economia local.

\section{REFERÊNCIAS}

ABRAMOVAY, Ricardo. Agricultura familiar e desenvolvimento territorial. Revista da ABRA, Brasília, v. 28, n. 1, p. 2, 1998.

Amazônia: por uma economia do conhecimento da natureza. São Paulo: Elefante, 2019. $108 \mathrm{p}$.

ALMEIDA, Débora; ALVES, Fernanda Basso; PIRES, Liliana. Governança em cadeias de valor da sociobiodiversidade: experiências e aprendizados de grupos multi-institucionais do Castanha do Brasil e Borracha-FDL no Acre. Brasília, DF: GIZ, Núcleo Maturi, UICN, WWF-Brasil, 2012.

ARROW, K. J. Increasing returns: historiographic issues and path dependence. The European Journal of the History of Economic Thought, v.7, n.2, p.171-180, 2000.

ATLAS BRASIL. Atlas do Desenvolvimento Humano no Brasil 2014. Brasília, DF: PNUD, 2014.

BENCHIMOL, Samuel. Amazônia: a guerra na floresta. Rio de Janeiro: Civilização Brasileira, 1992.

BENNETT, E. L.; ROBINSON, J. G. Hunting of wildlife in tropical forests: implications for biodiversity and forest peoples. Nova York: Columbia University, 2000.

BORYS, Bryan; JEMISON, David B. Hybrid arrangements as strategic alliances: Theoretical issues in organizational combinations. Academy of Management Review, Nova York, v. 14, n. 2, p. 234249, 1989. 
BRASIL. Ministério do Desenvolvimento Agrário-MDA; Ministério do Meio Ambiente-MMA; Ministério do Desenvolvimento Social e Combate à Fome-MDS. Plano Nacional de promoção das cadeias de produtos da Sociobiodiversidade. Brasília, DF, 2009.

BRASIL. Ministério do Meio Ambiente - MMA. Plano Amazônia Sustentável: diretrizes para o desenvolvimento sustentável da Amazônia Brasileira. Brasília, DF, Ministério do Meio Ambiente, 2008.

BRESSER-PEREIRA, Luiz Carlos; GALA, Paulo. Macroeconomia estruturalista do desenvolvimento. Brazilian Journal of Political Economy, Reino Unido, v. 30, n. 4, p. 663-686, 2010.

CAVALCANTE, Pedro; PIRES, Roberto. Governança pública: construção de capacidades para a efetividade da ação governamental. Nota Técnica. n. 24. Diretoria de Estudos e Políticas do Estado, das Instituições e da Democracia - Diest. Brasília, DF: IPEA, 2018.

CAZELLA, Ademir A.; BONNAL, Philippe; MALUF, Renato S. (orgs). Agricultura familiar: multifuncionalidade e desenvolvimento territorial no Brasil. Rio de Janeiro: Mauad X, 2009.

CHANG, Ha-Joon. The political economy of industrial policy. Nova York: St. Martin's Press, 1996.

COASE, Ronald H. The Nature of the Firm. Econômica, Rio de Janeiro, v. 4, n. 16, p. 386-405, 1937.

DAVIS, Lance; NORTH, Douglass. Institutional change and American economic growth: A first step towards a theory of institutional innovation. The Journal of Economic History, Cambridge, v. 30, n. 1, p. 131-149, 1970.

DINGWERTH, Klaus; PATTBERG, Philipp. Global governance as a perspective on world politics. Global governance: a review of multilateralism and international organizations, Estados Unidos, v. 12, n. 2, p. 185-204, 2006.

DOSI, G. Perspective on Evolutionary Theory. Science and Public Policy, Reino Unido, v.18, p.353-361, dez.1991.

EUROMONITOR. Beauty and Personal Care Market Research Reports 2018. Disponível em: www.euromonitor.com/beauty-and-personal-care. Acesso em: 27 jul.2019.

FARINA, E. M. M. Q. Competitividade e coordenação de sistemas agroindustriais: um ensaio conceitual. Revista Gestão \& Produção, São Carlos, SP, v. 6, n. 3, p. 147-161, 1999.

FARINA, E. M. M. Q.; AZEVEDO, P. F de. Política industrial e defesa da concorrência: considerações sobre a experiência brasileira nos anos 90. Economia, Rio de Janeiro, v. 2, n. 2, p. 513-547, 2001.

FARINA, E. M. M. Q.; SAES, M. S. M.; AZEVEDO, P. F. Competitividade: mercado, estado e organizações. São Paulo: Singular, 1997. 
FERRO, Ana Flávia Portilho; BONACELLI, Maria Beatriz Machado; ASSAD, Ana Lúcia Delgado. Oportunidades tecnológicas e estratégias concorrenciais de gestão ambiental: o uso sustentável da biodiversidade brasileira. Gestão \& Produção, São Carlos, SP, v. 13, n. 3, p. 489-501, 2006.

FIANI, Ronaldo. Cooperação e conflito: instituições e desenvolvimento econômico. São Paulo: GEN Atlas, 2011.

FIANI, R. Arranjos institucionais e desenvolvimento: o papel da coordenação em estruturas híbridas. In: GOMIDE, A. A.; PIRES, R. R. C. Capacidades estatais e democracia: arranjos institucionais de políticas públicas. Brasília, DF: Ipea, 2014.

FOLEY, Jonathan A. et al. Amazonia revealed: forest degradation and loss of ecosystem goods and services in the Amazon Basin. Frontiers in Ecology and the Environment, v. 5, n. 1, p. 25-32, 2007.

FRANKEL, Jeffrey A. The natural resource curse: a survey. National Bureau of Economic Research. Cambridge, MA, n. 02138, mar. 2010.

GERTLER, Meric S. Rules of the game: The place of institutions in regional economic change. Regional Studies, v. 44, n. 1, p. 1-15, 2010.

GIACOMINI, Corrado; MANCINI, Maria Cecilia. Organisation as a key factor in Localised AgriFood Systems (LAFS). Bio-based and Applied Economics Journal, Itália, v. 4, n. 1050-201685771, p. 17-32, 2015.

GOMIDE, Alexandre de Ávila; PIRES, Roberto. Capacidades estatais e democracia: a abordagem dos arranjos institucionais para análise de políticas públicas. Brasília, DF: Ipea, 2014.

HOLLINGSWORTH, J. Rogers. Doing institutional analysis: implications for the study of innovations. Review of international political economy, v. 7, n. 4, p. 595-644, 2000.

JOSSELIN, Daphne; WALLACE, William. Non-state actors in world politics: a framework. In: . Non-state actors in world politics. London: Palgrave Macmillan, 2001. p. 1-20.

LACHER, Hannes. Putting the state in its place: the critique of state-centrism and its limits. Review of International Studies, Reino Unido, v. 29, n. 4, p. 521-541, 2003.

MAKISHI, F.; VEIGA, J. P. C.; ZACARELI, M. A. Regulating Local Environmental Standards Through Private Incentives. In: BECCHIS, Franco; ASQUER, Albertor; RUSSOLILLO, Daniele. (orgs.). Handbook: the political economy of local regulation. London: Palgrave Macmillan, 2017. p. 287-295.

MAKISHI, F.; ZACARELI, M. A.; VEIGA, J. P. C. Impactos socioambientais dos produtos florestais não madeireiros: estudos de caso da Amazônia Brasileira. Revista Eletrônica de Investigação e Desenvolvimento, Moçambique, v. 4, p. 1-18, 2015. 
MALHI, Yadvinder et al. Climate change, deforestation, and the fate of the Amazon. Science, Estados Unidos, v. 319, n. 5860, p. 169-172, 2008.

MARQUES, E. Governo, atores políticos e governança em políticas urbanas no Brasil e em São Paulo: conceitos para uma agenda de pesquisa futura. In: MENICUCCI, T. M.; GONTIJO, J. G. (orgs.). Gestão e políticas públicas no cenário contemporâneo: tendências nacionais e internacionais. Rio de Janeiro: Fiocruz, 2016.

MATHEWS, M. R. Twenty five years of social and environmental accounting research. Accounting, Auditing \& Accountability Journal, v.10, n.4, p.481-531, Oct.1997.

MAURY, Cilulia Maria. Biodiversidade brasileira: avaliação e identificação de áreas e ações prioritárias para a conservação, utilização sustentável e repartição dos benefícios da biodiversidade nos biomas brasileiros. Brasília, DF: MMA/SBF, 2002. 404 p.

MÉNARD, C. Hybrid organizations. Alliances, joint ventures, networks, and other" strange" animals. In: GIBBONS, R.; ROBERTS, J. Handbook of organizational economics. Princeton: University Press Princeton, 2010.

MEYER, Margaret; MILGROM, Paul; ROBERTS, John. Organizational prospects, influence costs, and ownership changes. Journal of Economics \& Management Strategy, v. 1, n. 1, p. 9-35, 1992.

MOURA, Adriana Maria Magalhães de (org.) Governança ambiental no Brasil: instituições, atores e políticas públicas. Brasília, DF: Ipea, 2016.

MULS, Leonardo M. Desenvolvimento local, espaço e território: o conceito de capital social e a importância da formação de redes entre organismos e instituições locais. Revista Economia, Brasília, v.9, n.1, p. 1-21, jan./abr. 2008.

MURPHY, K.; SHLEIFER, A.; VISHNY, R. W. Industrialization and the big push. Journal of political economy, v. 97, n. 5, p. 1003-1026, 1989.

NAYYAR, Deepak; COURT, Julius. Towards global governance. In: Governing globalization: issues and institutions. Oxford: Oxford UP, 2002. p. 3-18.

NAUGHTON-TREVES, L.; HOLLAND, M. B.; BRANDON, K. The role of protected areas in conserving biodiversity and sustaining local livelihoods. Annual Review of Environment and Resources, v.30, p.219-252, nov.2005.

NORTH, Douglass C. Institutions, transaction costs, and the rise of merchant empires. The political economy of merchant empires, Cambridge, v. 22, p. 22-40, 1991.

NORTH, Douglass C. et al. Institutions, institutional change and economic performance. Cambridge, RU: Cambridge university press, 1990. 
PAGE, S. E. Path dependence. Quarterly Journal of Political Science, Chicago, n.1, p.87-115, 2006.

PECQUEUR, B. (ed.). Dynamiques territoriales et mutations économiques. Paris: l'Harmattan, 1996.

PIERSON, Paul. Increasing returns, path dependence, and the study of politics. American political science review, v. 94, n. 2, p. 251-267, 2000.

Politics in time: history, institutions, and social analysis. Princeton, NJ: Princeton University Press, 2004.

POLANYI, Karl. The great transformation. Boston, EUA: Beacon press, 1944.

RENTING, Henk et al. Exploring multifunctional agriculture. A review of conceptual approaches and prospects for an integrative transitional framework. Journal of environmental management, v. 90, p. S112-S123, 2009.

RHODES, Roderick Arthur William. The new governance: governing without government. Political studies, v. 44, n. 4, p. 652-667, 1996.

RISSE-KAPEN, Thomas et al. Bringing transnational relations back in: Non-state actors, domestic structures and international institutions. Cambridge, RU: Cambridge University Press, 1995.

ROSENAU, Pauline Vaillancourt (ed.). Public-private policy partnerships. Londres: MiT press, 2000.

ROSENSTEIN-RODAN, Paul N. Problems of industrialisation of eastern and south-eastern Europe. The economic journal, v. 53, n. 210/211, p. 202-211, 1943.

ROS-TONEN, M. A. F. et al. Forest-related partnerships in Brazilian Amazonia: there is more to sustainable forest management than reduced impact logging. Forest Ecology and Management, v. 256, n. 7, p. 1482-1497, 2008.

SACHS, J. D.; WARNER, A. M. The curse of natural resources. European economic review, v. 45, n. 4 , p. 827-838, 2001.

SANTOS, Daniel et al. Índice de progresso social na Amazônia brasileira: IPS Amazônia 2018. Belém, PA: Imazon. Social Progress Imperative, 2018.

SANTOS, Manoela Silveira dos; STAMM, Cristiano; SHIKIDA, Pery Francisco Assis. Inovação, economia dos custos de transação e gestão da cadeia de suprimento: uma discussão teórica. Revista Política e Planejamento Regional, Rio de Janeiro, v. 1, n. 2, p. 257-272, jul./dez. 2014.

SCHMID, A. Allan. Conflict and cooperation: institutional and behavioral economics. Nova Jersey, EUA: Wiley \& Sons, 2008. 
SCHNEIDER, Sergio. A pluriatividade na agricultura familiar. Rio Grande do Sul: SciELO-Editora da UFRGS, 2003.

SKOLE, David L. et al. Physical and human dimensions of deforestation in Amazonia. Bio Science, Reino Unido, v. 44, n. 5, p. 314-322, 1994.

STIGLITZ, Joseph E. Capital-market liberalization, globalization, and the IMF. Review of Economic Policy, Oxford, v. 20, n. 1, p. 57-71, 2004.

THOMPSON, J.; SCOONES, I. Addressing the dynamics of agri-food systems: an emerging agenda for social science research. Environmental science \& policy, v. 12, n. 4, p. 386-397, 2009.

VAN DEN BROEK, Jos; SMULDERS, Hubb. A evolução de um sistema de inovação regional transfronteiriço: uma perspectiva institucional. In: Documento da conferência RSA European Conference, 2013.

VILPOUX, Olivier. Desempenho dos arranjos institucionais e minimização dos custos de transação: transações entre produtores e fecularias de mandioca. Revista de Economia e Sociologia Rural, Brasília, DF, v. 49, n. 2, p. 271-294, 2011.

WILLIAMSON, Oliver. E. Markets and hierarchies: analysis and antitrust implications. New York: Free Pr, 1975.

. The mechanisms of governance. Reino Unido: Oxford University Press, 1996.

. Public and private bureaucracies: a transaction cost economics perspective. Journal of

Law, Economics, \& Organization, Reino Unido, v.15, n.1, p. 306-342, 1999. 